\title{
Pioneers in the Scientific Study of Neonatal Jaundice and Kernicterus
}

\author{
Thor Willy Ruud Hansen, MD, PhD
}

\begin{abstract}
Neonatal jaundice must have been noticed by caregivers through the centuries, but the scientific description and study of this phenomenon seem to have started in the last half of the 18th century. In 1785 Jean Baptiste Thimotée Baumes was awarded a prize from the University of Paris for his work describing the clinical course in $\mathbf{1 0}$ jaundiced infants.

The work by Jaques Hervieux, which he defended for his doctor of medicine degree in 1847, was, in many respects, a landmark. He had autopsied 44 jaundiced infants and apparently had clinical observations on many others. His descriptions of pathoanatomical findings were very detailed and systematic. A number of his clinical observations are still thought to be accurate today, such as the essentially benign nature of neonatal jaundice in most cases, the appearance of neonatal jaundice during the first 2 to 4 days of life as well as its disappearance within 1 to 2 weeks, and the cephalocaudal progression of jaundice. He described jaundice of the brain in 31 of his 44 autopsied cases, with variable intensity of staining.
\end{abstract}

Johannes Orth was an assistant to the famous Virchow in Berlin, when in $\mathbf{1 8 7 5}$ he published the results of an autopsy of a jaundiced term infant. The brain was notable for an intense yellow staining of the basal ganglia, the wall of the third ventricle, the hippocampus, and the central parts of the cerebellum. While the contribution of Orth was limited to this single case report, in 1903 Christian Schmorl presented the results of his autopsies of $\mathbf{1 2 0}$ jaundiced infants to the German Society for Pathology. All of these infants' brains were jaundiced, but only 6 cases demonstrated a staining phenomenon similar to that previously described by Orth. Schmorl coined the term kernicterus (jaundice of the basal ganglia) for this staining pattern.

Although the following century of scientific study has added an enormous amount of information about the epidemiology and pathophysiology of neonatal jaundice and kernicterus, the contributions of Hervieux, Orth, and Schmorl will undoubtedly continue to be seen as historical landmarks in our quest for understanding of these phenomena. Pediatrics 2000;106(2). URL: http://www. pediatrics.org/cgi/content/full/106/2/e15; neonatal jaundice, kernicterus, hyperbilirubinemia, history.

$\mathrm{N}$ eonatal jaundice is a very common phenomenon, and it has undoubtedly been noticed and reflected on by caregivers since the dawn of human history. We do not know what

From the Section on Neonatology, Department of Pediatrics, Rikshospitalet, University of Oslo, Oslo, Norway.

Received for publication Jan 11, 2000; accepted Mar 27, 2000.

Reprint requests to (T.W.R.H.) Section on Neonatology, Department of Pediatrics, Rikshospitalet, N-0027 Oslo, Norway. E-mail: t.w.r.hansen@ klinmed.uio.no

PEDIATRICS (ISSN 0031 4005). Copyright ( 2000 by the American Academy of Pediatrics. thoughts arose or what explanations were proffered in those early days. However, descriptions of jaundiced infants appear in some very early medical textbooks. Morgagni supposedly described and discussed 15 jaundiced infants, all of them his own (as cited by Hervieux ${ }^{1}$ ).

Kernicterus is the German term for jaundice of the basal ganglia of the brain and is sometimes seen in infants dying with extreme jaundice. This complication was primarily seen in infants with severe hyperbilirubinemia accentuated by hemolysis as in Rhesus-negative immunization. However, kernicterus has also been described in the absence of hemolysis. Afflicted infants often died during the acute phase, and a neurological condition with choreoathetosis, gaze paresis, sensorineural deafness, and occasional mental retardation was observed in survivors.

The Work of Jean Baptiste Thimotée Baumes and Others During the Late 18th and Early 19th Centuries

In 1785 the University of Paris announced a prize challenge for the best work on the following topic: "Describe neonatal jaundice, and distinguish those circumstances in which treatment is needed and those in which we must only await the natural course." The price was awarded to Jean Baptiste Thimotée Baumes for his work: Traité de l'Ictère ou Jaunisse des Enfans des Naissance (English translation: Treatise on Icterus or Jaundice of Newborn Infants). ${ }^{2}$

Apparently this work must have been a hot commodity in the book stores-a revised edition was published in 1806 because the first edition had long been sold out. ${ }^{2}$ In his preface to the second edition, the author modestly lets us know that "my publisher wanted to republish it, and I did not object to his point of view." Medical students seem to have been among the eager readers of the first edition. Some of these may have taken its message so much to heart that they subsequently were unable to distinguish Baumes' thoughts from their own. Thus, in his preface to the second edition, Baumes in strong terms denounces François Bidault's doctoral thesis from $1804^{3}$ (at the University of Paris) as having been plagiarized nearly in toto from his 1785 work. Clearly, scientific shortcuts were not novel to the twentieth century!

The treatise by Baumes was based on his observations of 10 jaundiced infants, although not all were clearly described in the second edition of his work. The first case was Baumes' own daughter, Justine. He believed that delayed meconium passage was a primary cause of neonatal jaundice, and espoused breast milk, particularly colostrum, from the infant's 
own mother as the best remedy for this problem. His thoughts on the reabsorption of bile from the duodenum seem to be confirmed by our present knowledge about the enterohepatic circulation of bilirubin. Some of the infants described by Baumes exhibited either the somnolence or the anorexia subsequently associated with significant neonatal jaundice. None of the pharmacological therapies espoused by Baumes have withstood the test of time, and they are unknown today.

During the first half of the 19th century several doctoral theses at the University of Paris were on the topic of neonatal jaundice. ${ }^{3-8}$ The format for these seems to have consisted of presentation of a limited number of case reports, accompanied by reflections and speculations around the phenomenon. The strong conviction with which these reflections were offered occasionally stands in stark contrast to the lack of any proof of their veracity. The literature cited is primarily that of some classical medical texts plus the work of Baumes.

\section{Jaques François Édouard Hervieux (1818-1905)}

In 1847 a thesis on neonatal jaundice was submitted to the University of Paris, which, in many ways, departed significantly in form and scope from the preceding works on the same subject. The university examiners apparently recognized the high quality of this work, because they rewarded it with the top grade-trés satisfait (very satisfactory).

The author, Jaques François Édouard Hervieux (Fig 1), was born in Louviers, France, on Septem-

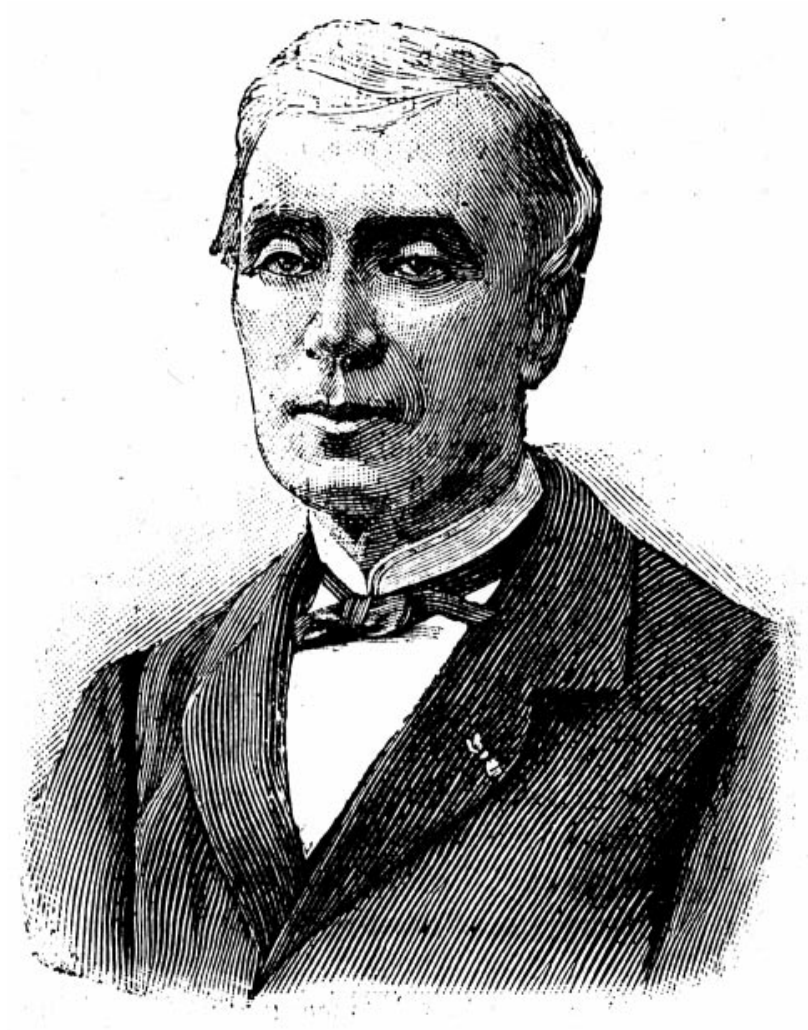

Fig 1. Jaques François Édouard Hervieux (1818-1905). Reproduced by permission from the Bibliothèque Interuniversitaire de Médecine, Paris, France. ber 3, 1818. He went to high school in Rouen and completed his bachelor-of-letters in 1838. Moving to Paris, he received a bachelor-of-science in 1841, and then went on to medical school. The thesis he submitted and defended for the doctor of medicine degree was entitled "De l'Ictère des Nouveau-nés " (English translation: On the Jaundice of Newborns). ${ }^{1}$

In the introductory part of his thesis, Hervieux discussed works by previous authors. Thus the prize-winning effort by Baumes ${ }^{2}$ was critiqued. Baumes' claim that delayed meconium passage was a cause of neonatal jaundice was dismissed by Hervieux as "without doubt ingenious, but never the less only an intellectual theory." Hervieux also discussed the work of Billard, ${ }^{7}$ who apparently had observed a reasonable number of cases and performed a large number of autopsies. His primary criticism was that Billard's observations on jaundice were merely incidental and not the focus of his study-" "for this reason there are numerous omissions and a manifest disagreement between his results and mine."

Hervieux's thesis seems, compared with other medical publications of that time, to be nearly modern in its systematic approach to the subject. He had systematically collected observations, primarily at the autopsy table, but also in the infant nursery. He began his thesis by discussing a proper definition of the term jaundice and then went on to discuss classification and possible causes.

In his discussion of the work of some of his predecessors, his disdain was quite obvious and occasionally voiced in terms that would have raised eyebrows in modern-day medical journal editorial offices. Some examples may be of interest: "I do not take seriously the opinion of Andrieu, who imagines that the pressure of a midwife's or physician's hands on the baby's face may be a cause of jaundice. Even less the observation by Anhorn who has seen jaundice produced in newborns by immersion in cold water." On Baumes' theory that meconium retention is an important cause of neonatal jaundice, ${ }^{2}$ Hervieux has the following comment: "Baumes supports his opinion with a very small number of observations, and then concludes with astonishing ease to the great majority of cases. A simple reflection will disprove this hypothesis." He is arguably most scathing in his general criticism of his predecessors' hypotheses: "Thus collapses, as one will see, all the scaffolding regarding causes (of jaundice) constructed by authors who have occupied themselves with causes of jaundice in newborns. Hazardous conjecture, sterile hypotheses, and opinions conceived far from the beds of sick babies and from the autopsy room, this is all we have. We need to agree that the abundance of such [theories of] causes has served no purpose but to impoverish science...."

\section{Hervieux's Findings}

Having dismissed most of the theories and work of his predecessors (in some respects prematurely, as subsequent research has shown), Hervieux went on to present his own findings. He reported on 45 cases, 44 of which had died and were autopsied by him. However, he had obviously also observed a number 
TABLE 1. Summary of Jacques François Édouard Hervieux's Clinical and Epidemiological Observations on Neonatal Jaundice ${ }^{1}$

1. The cause of neonatal jaundice is not known, but one can state that jaundice in the neonate is a manifestation of a recently established function that for a limited time exceeds its physiological limits.

2. Neonatal jaundice is a physiological condition.

3. Neonatal jaundice is, by itself, never fatal

4. Neonatal jaundice appears during the first 2 to 4 days of life and lasts for 1 to 2 weeks. It never reappears in the following months.

5. There is a cephalocaudal progression in the appearance of jaundice - the extremities are always last to be affected. When jaundice disappears, the order is reversed.

6. Neonatal jaundice is very common-approximately two thirds of all infants are affected. The prognosis in the absence of complicating conditions is benign.

7. Jaundice is not seen in foundlings who are wet-nursed, or in infants nursed by a woman who gave birth a long time ago.

8. The most frequent complicating conditions are scleredema, diarrhea, and thrush.

9. Treatment consists of combating the complicating conditions. Isolated neonatal jaundice does not need treatment.

10. In neonatal jaundice, the yellow color is found throughout the tissues of the body, including the brain.

of infants who survived (he did not specify how many), and who formed the basis for his descriptions of the epidemiology and clinical course of neonatal jaundice. These observations are summarized in Table 1 . As will be seen, a surprising number of these observations would fit into a textbook chapter even today.

Hervieux apparently performed autopsies on a large number of infants dying from a variety of causes: "Over a period of 6 months I opened on average 3 infants every day." An important cause of death seems to have been scleredema. Among 90 cases of scleredema, Hervieux found 31 to be jaundiced, while among his 45 cases of jaundice, 31 had scleredema, 15 had diarrhea, and 5 had thrush. He was adamant that jaundice was not the cause of death in any of these infants.

In his report on the autopsy findings, he went systematically through every organ system, starting with the skeleton. In general he found jaundice in every organ but with considerable variation. He suggested that the degree of jaundice of any given organ was related to its vascularity; the more highly perfused the organ, the more jaundiced it was likely to be. Thus, in the skeleton, the cranial bones were visibly jaundiced. The amount of detail in his examinations is astounding-having found 28 of 44 pairs of eyes to be jaundiced, he dissected membrane layers and arranged them according to how yellow they appeared. Hervieux had one disappointment in his study - the blood that he had obtained from each patient and had stored for subsequent analysis was destroyed by fermentation during a heat wave and could not be analyzed.

\section{Hervieux's Neuropathological Observations}

Hervieux described brain jaundice in 31 of 44 cases of neonatal jaundice. In all of these cases, clinical jaundice had been at its peak at the time of death, whereas in the 13 remaining cases, jaundice had only just appeared or was in the process of fading. He described the intensity of the brain jaundice as variable. Some brains were quite uniformly stained, while in other brains some regions were more heavily stained than others. Although he found jaundice of the striatum in rare cases, the patterns of staining that he described do not seem identical to that which subsequently became known as kernicterus. It is noteworthy that he found the cerebrospinal fluid to be jaundiced in all cases. In recent times biochemical analyses have confirmed the presence of significant amounts of bilirubin in cerebrospinal fluid. ${ }^{8-11}$

\section{A Brief Biographical Note on Hervieux}

During his professional career, Jaques François Édouard Hervieux continued to be a prolific worker and published a large number of articles and monographs on various obstetrical and neonatal/perinatal problems. He retired from clinical work as chief of the maternity hospital at 65 years old, but at 70 years old he was appointed director of the immunization service. In 1892 he was awarded the rosette of the Legion of Honor, and in 1896 he was honored with the presidency of the Medical Academy. He died on March 31, 1905 at 86 years old.

\section{Johannes Orth (1847-1923)}

The honor of having published the first description of the pathoanatomical picture of kernicterus may belong to Johannes Orth (Fig 2). He was born in Wallmerod, Germany, in 1847, the year that Her-

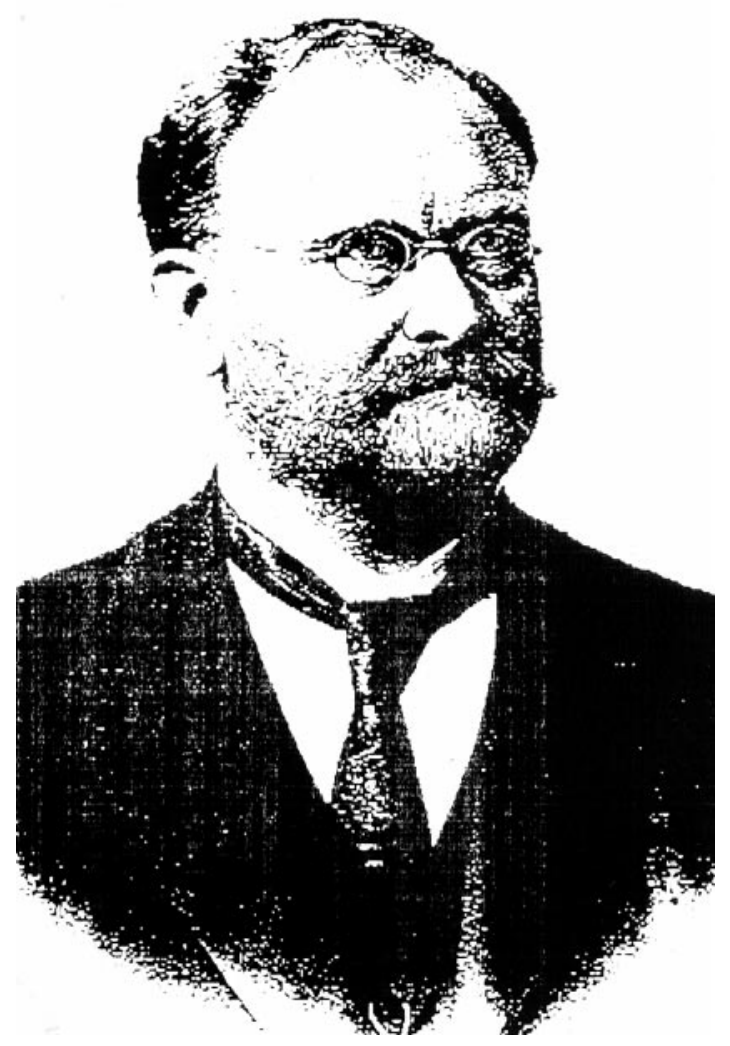

Fig 2. Johannes Orth (1847-1923). Reproduced by permission from the Berliner Medizinhistorische Museum, Charité, Berlin, Germany. 
vieux defended his thesis. He graduated from medical school in Bonn in 1870 and immediately embarked on a career in pathology.

Having defended his doctorate in 1872, he became an assistant to the famous Virchow in Berlin in 1873. In 1878 he became a full professor in Göttingen and remained there until he was called to Berlin to take over Virchow's position in 1902. During most of his career, he focused on the pathology of infectious diseases. He wrote a number of widely used textbooks and had a reputation as an excellent teacher. He died in 1923 from cholangitis after repeated bouts of jaundice attributable to bile stones.

\section{Orth's Description of Kernicterus}

Orth's work on neonatal jaundice was performed while he was still an assistant to Virchow. In his article, which primarily focused on pigment crystals in various organs, he described a term female infant who was born nonicteric, but who became jaundiced soon after birth. ${ }^{12}$ The child died at 2 days of age with very pronounced jaundice, which was apparently her only sign/symptom. At autopsy all organs were found to be jaundiced, but with an underlying pallor that may perhaps point to the existence of anemia. The brain was intensely yellow, but with much more intense staining of the basal ganglia, the wall of the third and fourth ventricles, the hippocampus, and the central parts of the cerebellum. On microscopic examination of the latter, the granular layer was found to be heavily stained. Orth also noted that although neurons of the basal ganglia were stained, the glial elements were not.

In his discussion Orth noted that in jaundiced adults the brain was, in his experience, hardly ever significantly colored. Today we would explain this based on the differing abilities of conjugated bilirubin (primarily seen in adult jaundice) and unconjugated bilirubin (primarily seen in neonatal jaundice) to cross the blood-brain barrier. Orth finally speculated that the intense jaundice in this infant might have had hematologic causes, a speculation, which, in the light of later knowledge, may well have been precisely on target.

\section{Christian Georg Schmorl (1861-1932)}

To Christian Schmorl belongs the distinction of having coined the tern kernicterus (jaundice of the nuclei), which has subsequently been used both to describe a pathoanatomical picture seen at autopsy in those who died, as well as a neurological syndrome in survivors of extreme jaundice. Christian Georg Schmorl (Fig 3) was born in Mügeln, Sachsen, Germany, on May 2, 1861. After high school he studied mathematics for a year at the University of Freiburg, and then switched to medicine in Leipzig. After graduation in 1887, he immediately embarked on a career in pathology under the tutorship of the famous Birch-Hirschfeld, and he defended his doctorate in 1892 on the topic of eclampsia. In the following year he published a monograph on the same topic, supposedly the first large review of the pathologic anatomy of this complication of pregnancy.

In 1894 he was appointed chief of pathology in

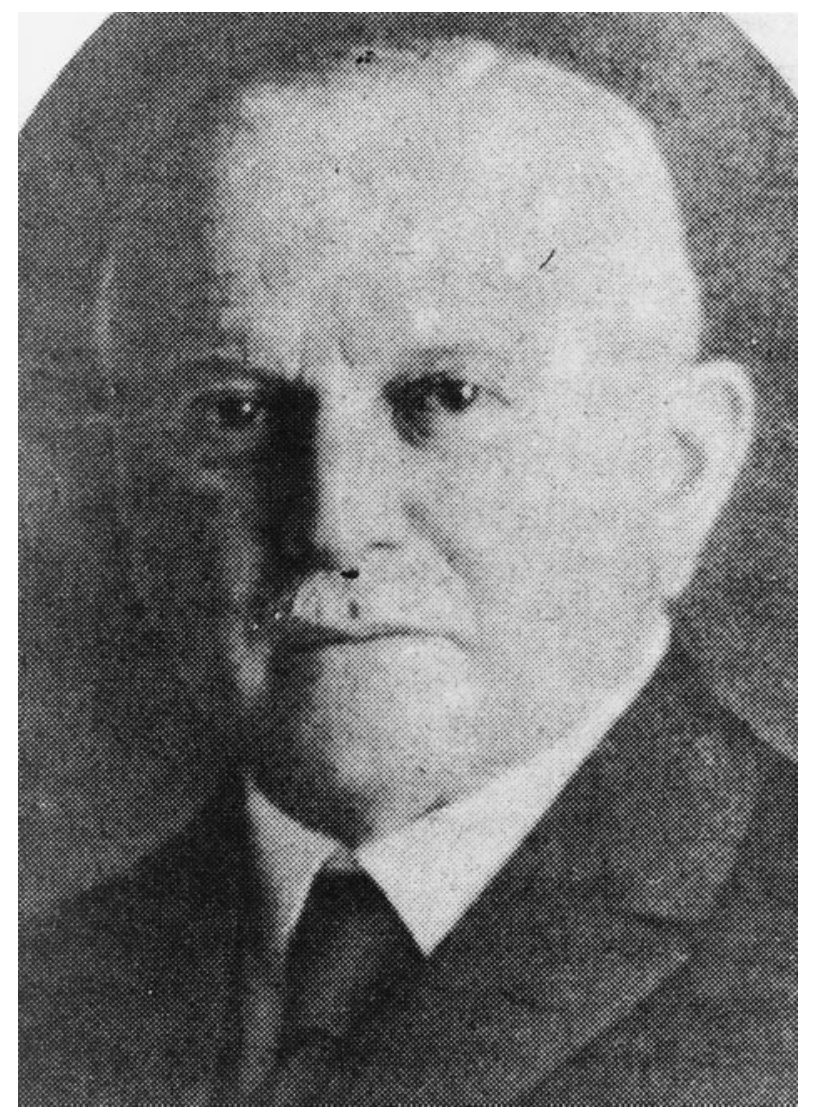

Fig 3. Christian Georg Schmorl (1861-1932). Reproduced by permission from the Sächsische Landesbibliotek, Staats und Universitätsbibliotek Dresden, Dresden, Germany.

Dresden where he remained for nearly 4 decades until his retirement in 1931. His publications covered more or less the entire field of pathology, but he was particularly interested in the skeletal system. His major work in this field, Die Gesunde und Kranke Wirbelsäule (English translation: The Healthy and Sick Spine) was published just a few months before his death. His death from septicemia on August 14, 1932 was caused by an infection in a finger, which he nicked during the dissection of a spine.

\section{Schmorl's Study of Brain Pathology in Neonatal Jaundice}

In his landmark paper Schmorl described his findings from the autopsies of 280 neonates, of whom 120 were jaundiced at the time of death. ${ }^{13}$ In the majority of these cases $(114 / 120)$, he found the brain to be diffusely yellow. He noted that the intensity of the brain color paralleled that of the face, which is often the most intensely jaundiced part of an infant's body, as also described by Hervieux. ${ }^{1}$ This diffuse yellow brain coloring is notable because it corresponds to what animal research has shown us during the past 50 years: bilirubin will be present in the brain in any individual with significant unconjugated hyperbilirubinemia.

However, in 6 of the 120 brains from jaundiced individuals, Schmorl found spots of much more intense coloring, notably in the basal ganglia and medulla oblongata. He very appropriately quoted Orth 
as having described this pattern previously. Of these 6 cases, only 2 were so well conserved that a more detailed study was possible, and it is on these 2 cases that Schmorl's presentation was primarily based. He apparently had brought with him to the meeting tissue specimens preserved in formaldehyde, which he showed to the audience. Colored illustrations accompanied the printed version of his article (Fig 4). ${ }^{13}$

Schmorl noted that unless the specimens were preserved in formaldehyde, the color would disappear. A similar observation led Brodersen and Bartels ${ }^{14}$ to examine brain tissue for the possible presence of bilirubin oxidizing enzyme in the brain, concluding that such an enzyme was indeed present on the inner mitochondrial membrane of brain cells. Work in our group has since confirmed and expanded upon these observations. ${ }^{15-20}$

In the brains that Schmorl examined, the jaundiced nuclei were very sharply demarcated and, therefore, contrasted clearly with the color of the surrounding tissue. Because of this sharp demarcation and the predilection for staining of the nuclei, Schmorl pro- posed the term kernicterus. He further suggested that the yellow color was not simply attributable to saturation of the tissue with bile pigments, such as was the case (he believed) with eg, skin, but to binding of the bile pigments to specific structural elements in the tissue.

Microscopic examination of the tissue supported this hypothesis. Some neurons in the nuclei were strongly colored, while others had a more pale yellow color. These latter cells exhibited changes that suggested that they were in the process of dying. Yellow color was also noted in the axons and dendrites, while an underlying network, which Schmorl thought must be of glial origin, was not visibly stained. Subsequent studies have shown that there is a difference between neurons and glia in their sensitivity to bilirubin toxicity, ${ }^{21}$ although the specific reason for these differences is not known. Schmorl also hypothesized that bilirubin, perhaps under special circumstances, binds more avidly to certain neurons than to others. In recent years an in vitro study
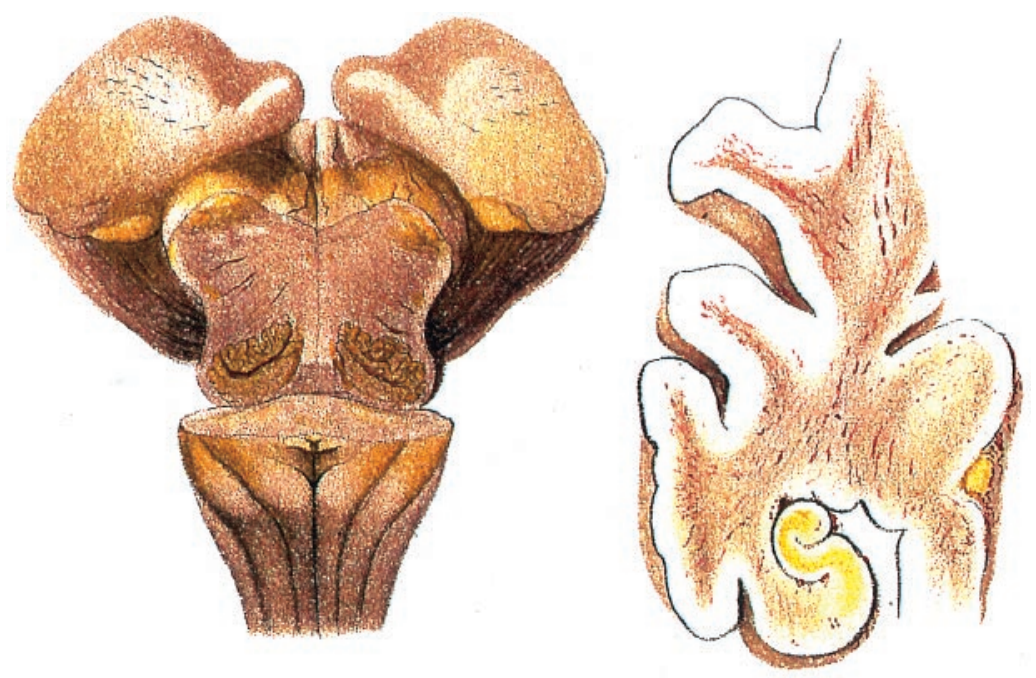

Fig 4. Color figure from the 1904 publication by Schmorl, ${ }^{13}$ illustrating the findings that led him to coin the term kernicterus (jaundice of the basal ganglia). Reproduced by permission from Urban and Fischer Verlag, Jena, Germany.

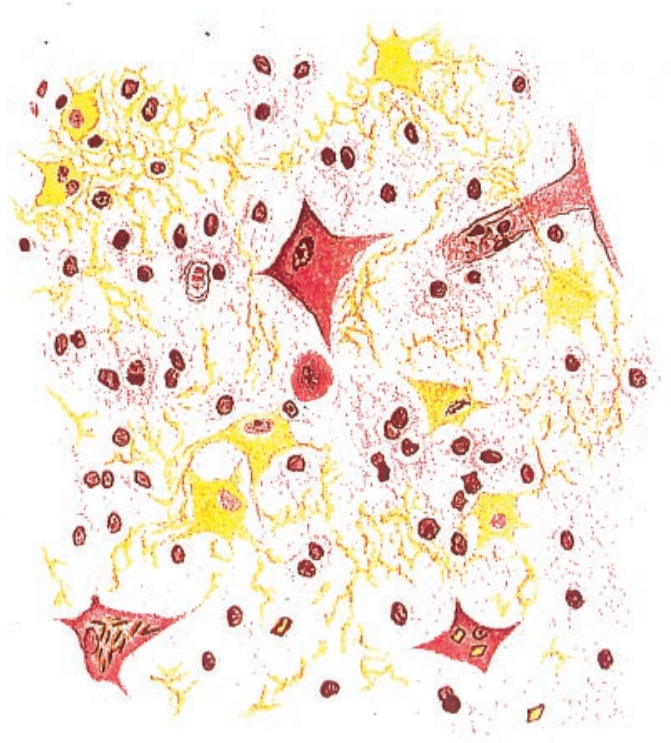


of bilirubin binding to brain slices seemed to support Schmorl's hypothesis of differential binding. ${ }^{22}$

Schmorl posed a question that has echoed in the bilirubin literature almost to the present: Do the neurons die first and then become stained by the bile pigment, or does uptake/binding of bile pigment precede or even cause death? Although the mechanism of cell death in bilirubin toxicity is still under investigation and debate, there certainly is ample evidence that bilirubin is bound to and taken up into cells. Once inside a cell bilirubin causes that cell to die. The speed of the process depends, among other things, upon bilirubin concentration and can be stopped or reversed up to a certain point. ${ }^{23}$

As far as patient characteristics, Schmorl was unable to find any that distinguished the six patients with kernicterus from the remaining 114 without this staining pattern. Thus, two of the six infants were about two months preterm, while the rest were term. Both the intensity and duration of jaundice varied. Schmorl gave only limited clinical details about the patients, but hinted that most of them died from other causes (pneumonia, enteritis), although he made specific mention that one of the infants had absolutely no evidence of other organ pathology that might explain death.

\section{DISCUSSION}

Hervieux's thesis has been cited in the literature as the first scientific study of neonatal jaundice. Whether this is true must, to some extent, depend on how the term science is understood. Although it would seem that most of the studies and publications that preceded Hervieux's work did not adhere to standards that we would now regard as scientific, judging those works by present-day standards is probably inappropriate.

But it seems fair to say that Hervieux's work surpassed the prevailing standards of his epoch in his systematic approach, his focus on a particular problem which he pursued with great attention to the minutiae, and his attitude of critical questioning of the established truths. A surprising number of his clinical observations would still be regarded as accurate today. It is an interesting historical tidbit that exactly 100 years after the publication of Hervieux's thesis, Louis K. Diamond received the 1947 E. Mead Johnson Award for Research in Pediatrics based on his work "Umbilical Vein Catheterization and Replacement Transfusion as a Treatment for Erythroblastosis Fetalis." ${ }^{24}$ Dr Diamond, of course, first used this procedure to remove sensitized red cells, and not to treat hyperbilirubinemia.

Schmorl's study seems to have been presented in a meeting of the German Society for Pathology, possibly in 1903, because this year is sometimes quoted when this work is referenced. The written version was published in $1904 .{ }^{13}$ Johannes Orth must have been present during this meeting, because a question from him is printed at the end of the article. Schmorl's study is, in many ways, reminiscent of the study published by Hervieux 57 years earlier, in that both physicians approached the subject in a very systematic fashion. Both physicians also had access to a volume of neonatal autopsy material that would stagger the imagination of a modernday pathologist.

Hervieux, Orth, and Schmorl each helped to lay the foundation on which subsequent clinical and basic science studies in bilirubin neurotoxicity were founded. A number of their observations and speculations have subsequently been shown to be very much on target. Although their analytical tools were limited, the precision of their observations gave these scientists/physicians a well-deserved place in the history of neonatal-perinatal research.

\section{Postscript}

Colleagues who have access to scientific publications on neonatal jaundice or bilirubin (articles, theses, pamphlets, book chapters/paragraphs) predating 1930 are kindly requested to contact me. I am also interested in information about depictions of jaundiced infants in novels, poems, or pictorial arts.

\section{ACKNOWLEDGMENTS}

Ms Bernadette Molitor, Bibliothèque Interuniversitaire de Médecine, Paris, France, was of great help in providing photocopies of several French theses and manuscripts from the 19th century.

Dr Jürgen Pfeiffer, Tübingen, Germany, provided biographical information on Drs Orth and Schmorl.

Mrs Annelise Löhe-Vogel, Berlin, Germany, also kindly shared some biographical notes on her grandfather, Johannes Orth.

\section{REFERENCES}

1. Hervieux JFE. De l'Ictère des Nouveau-nés (English translation: On the Jaundice of Newborns). Paris, France: University of Paris; 1847. Doctoral thesis

2. Baumes JBT. Traité de l'Ictère ou Jaunisse des Enfans des Naissance (English translation: Treatise on Icterus or Jaundice of Newborn Infants). 2nd ed. Paris, France: Méquignon; 1806

3. Bidault F. Essai sur l'Ictère des Nouveau-nés. Paris, France: University of Paris; 1804. Doctoral thesis

4. Vaillant L. Dissertation sur l'Ictère des Nouveau-nés. Paris, France: University of Paris; 1816. Doctoral thesis

5. Denis P-S. De l'Ictère et de l'Endurcissement du Tissu Cellulaire des Enfans Nouveau-nés. Paris, France: University of Paris; 1824. Doctoral thesis

6. Bouton J-P. Thèse Pour le Doctorat en Médicine. Paris, France: University of Paris; 1838. Doctoral thesis

7. Billard C. Traité des Maladies des Enfans Nouveau-nés et a la Mamelle. Paris, France: JB Baillière; 1828

8. Meisel P, Jährig D, Jährig K. Bilirubin im liquor cerebrospinalis neugeborener. I. vergleichende untersuchungen des liqour cerebrospinalis bei bilirubinämie und ZNS-affektionen. Kinderartzl Prax. 1981;49:633-642

9. Meisel P, Jährig D, Jährig K. Bilirubin im Liquor cerebrospinalis neugeborener. II. Einflussfaktoren auf den bilirubingehalt des liquor cerebrospinalis. Kinderarztl Prax. 1982;50:370-378

10. Weyrauch P-C, Jährig K, Wiersbitsky S. Ergebnisse der liquoruntersuchungen bei neugeborenen. Kinderarztl Prax. 1973;41:447-454

11. Lee T-C, Hsia DY. Experimental studies on blood-spinal fluid barrier for bilirubin. J Lab Clin Med. 1959;54:512-524

12. Orth J. Ueber das Vorkommen von bilirubinkrystallen bei neugeborenen kindern. Virchows Arch Pathol Anat. 1875;63:447-462

13. Schmorl C. Zur Kenntnis des ikterus neonatorum, insbesondere der dabei auftretenden gehirnveränderungen. Verh Dtsch Pathol Ges. 1904; 6:109-115

14. Brodersen R, Bartels P. Enzymatic oxidation of bilirubin. Eur J Biochem. 1969;10:468-473

15. Hansen TWR, Allen JW. Bilirubin-oxidizing activity in rat brain. Biol Neonate. 1996;70:289-295

16. Hansen TWR, Allen JW. Oxidation of bilirubin by brain mitochondrial membranes-dependence on cell type and postnatal age. Biochem Molec Med. 1997;60:155-160

17. Hansen TWR, Tommarello S, Allen JW. Oxidation of bilirubin by rat brain mitochondrial membranes-genetic variability. Biochem Molec Med. 1997;62:128-131 
18. Hansen TWR, Tommarello S. Effects of phenobarbital on bilirubin clearance and metabolism in rat brain. Biol Neonate. 1998;73:106-111

19. Allen JW, Tommarello S, Carcillo J, Hansen TWR. Effects of endotoxemia and sepsis on bilirubin oxidation by rat brain mitochondrial membranes. Biol Neonate. 1998;73:340-345

20. Hansen TWR, Allen JW, Tommarello S. Oxidation of bilirubin in the brain - further characterization of a potentially protective mechanism. Molec Genet Metab. 1999;68:404-409

21. Notter MFD, Kendig JW. Differential sensitivity of neural cells to bili- rubin toxicity. Exp Neurol. 1986;94:670-682

22. Danbolt NC, Hansen TWR, Øyasæter S, Bratlid D, Storm-Mathiesen $\mathrm{J}$. In vitro binding of ${ }^{3}$ bilirubin to neurons in rat brain sections. Biol Neonate. 1993;63:35-39

23. Amit Y, Poznansky MJ, Schiff D. Bilirubin toxicity in a neuroblastoma cell line N-115: delayed effects and recovery. Pediatr Res. 1989;25: 360-372

24. Diamond LK. Erythroblastosis fetalis or hemolytic disease of the newborn. Proc R Soc Med. 1947;40:546-550 